\title{
Purpose, Procedure, and Contents of Counseling according to Tinnitus Interventions
}

\author{
Soon-Je Choi', Minseung Ku', TaeRim Lee², YeonWoo Sim², Jeeun Yoo', \\ Nor Farawaheeda Ab Shukor', Yerim Shin', In-Ki Jin ${ }^{3}$ \\ 'Department of Speech Pathology and Audiology, Graduate School, Hallym University, Chuncheon, Korea \\ ${ }^{2}$ Division of Speech Pathology and Audiology, College of Natural Sciences, Hallym University, Chuncheon, Korea \\ ${ }^{3}$ Division of Speech Pathology and Audiology, Research Institute of Audiology and Speech Pathology, College of Natural Sciences, Hallym University, \\ Chuncheon, Korea
}

Received: October 30, 2020

Revised: December 8, 2020

Accepted: December 9, 2020

\section{Correspondence:}

In-Ki Jin, PhD

Division of Speech Pathology and

Audiology, Research Institute

of Audiology and Speech Pathology,

College of Natural Sciences,

Hallym University, 1 Hallymdaehak-gil,

Chuncheon 24252, Korea

Tel: +82-33-248-2221

Fax: +82-33-256-3420

E-mail: inkijin@hallym.ac.kr
Tinnitus refers to the perception of ringing sounds in the ear that are not heard by others. Counseling plays a vital role in tinnitus intervention. Counseling provides correct information about tinnitus and hearing loss, corrects any misunderstandings related to tinnitus, and suggests precise alternative interventions for tinnitus. In this review, we aimed to examine the counseling contents in Tinnitus Retraining Therapy (TRT), Cognitive Behavioral Therapy (CBT), and Tinnitus Activities Treatment (TAT) to identify information that could be useful for counseling approaches and contents for the various tinnitus intervention methods. We searched Web of Science, Embase, Science Direct, and PubMed for relevant articles. Of the 5,283 articles, 31 were included in the final review of counseling contents for TRT, CBT, and TAT. Based on our findings, we were able to summarize the main contents of counseling in TRT, CBT, and TAT. Although the contents of counseling may vary depending on the individuals with tinnitus, our review provided information that may help audiologists or hearing professionals further understand the fundamentals of counseling for each tinnitus intervention. Our review may serve as a guideline for tinnitus counseling according to tinnitus interventions.

Key Words: Cognitive behavioral therapy, Counseling, Tinnitus, Tinnitus activities treatment, Tinnitus retraining therapy.

\section{INTRODUCTION}

이명(tinnitus)은 본인의 의사와 상관없이 머리에서 발생하는 소리를 인식하는 증상을 의미한다(McFadden, 1982). 이명의 대부분을 차지하는 감각신경성 이명의 경우, 주요한 기전은 체 성감각계(somatosensory system) 및 변연계 등으로 대표되는 뇌(brain) 영역에 의한 원인으로 보고하고 있다(Lee et al., 2020). 일반적으로, 감각신경성 이명이 발생한다면 그 기전을 명확하 게 규명하여 치료하는 것은 어렵다고 알려져 있다. 기전이 명확 하지 않은 감각신경성 이명의 중재(intervention) 방법으로 이 명재훈련치료(Tinnitus Retraining Therapy, TRT), 인지행동치 료(Cognitive Behavioral Therapy, CBT) 및 이명활동치료 (Tinnitus Activities Treatment, TAT)와 같은 심리행동적 접근

(cc) This is an Open Access article distributed under the terms of the Creative Commons Attribution Non-Commercial License (https://creativecommons.org/licenses/by-nc/4.0) which permits unrestricted non-commercial use, distribution, and reproduction in any medium, provided the original work is properly cited.
법들이 개발되었다(Henry \& Wilson, 2002; Scherer et al., 2014; Sweetow, 1985).

이명의 심리행동적 접근법들은 서로 다른 방식과 절차로 구 성되어 있으며 일반적으로 이명으로 인한 부정적인 반응과 부 작용을 줄이는 것을 목표로 한다. 예를 들어, 이명재훈련치료 는 부정적인 사고를 억제하고 이명에 대한 습관화(habituation) 를 목표로 하며(Scherer et al., 2014), 인지행동치료는 이명에 대한 오해와 잘못된 인식을 제거하고 부정적인 사고를 바로잡 는 것을 목표로 한다(Sweetow, 1985). 또한, 이명활동치료는 이 명으로 인해 발생하는 삶의 질 저하와 관련된 이차적인 문제들 을 파악하고, 대상자가 어려움을 호소하는 항목들의 개선을 목 표로 한다(Henry \& Wilson, 2002). 앞서 설명한 심리행동적 접근법들은 모두 상담을 주요한 구성 요소로 포함하고 있으나 각 중재법마다 상담의 주요 내용과 목적은 다르다. 예를 들어, 인지행동치료에서 상담의 목적은 사고와 감정 차이에서 오는 불안감을 이해시키고 행동과 인지적 반응을 유지하도록 하는 
것이고(Martinez-Devesa et al., 2010), 이명활동치료에서 상담의 내용은 이명으로 인한 이차적인 문제를 줄이는 구체적인 방법들 을 교육하는 데에 초점을 두고 있다(Tyler et al., 2006, 2007).

상담은 이명 중재에서 중요한 역할을 한다. Tyler et al.(2012) 은 상담과 이명 소리치료(sound therapy)를 병행하여 실시한 그룹과 상담만을 실시한 그룹을 대상으로 3 개월간 진행한 연 구를 통해 이명 중재에서 상담의 효과를 확인하고자 하였다. 연구 결과, 이명 설문지 점수의 감소로 정의한 중재 효과는 상 담과 소리치료를 병행한 그룹에서 $31.6 \%$, 상담만 실시한 그룹 에서 $16.7 \%$ 로 나타났으며, 그룹 간에 통계적으로 유의미한 차 이는 나타나지 않았다. 이러한 결과는 상담이 이명 중재에서 중 요한 구성 요소임을 시사한다.

이명 중재에서 상담은 필수적인 역할을 하고 있지만, 중재법 마다 진행하는 상담의 목적과 주요 내용에는 차이가 있다. 본 연구는 이명재훈련치료, 인지행동치료 및 이명활동치료 내 상 담의 목적과 각 상담에서 일반적으로 진행하는 주요 내용 및 절차를 제시하여 임상에서 효과적인 상담을 진행하기 위한 가 이드라인을 제시하고자 한다.

\section{DATA SELECTION PROCESS}

본 연구는 데이터베이스(Web of Science, Embase, Science Direct, and PubMed)를 통해 "tinnitus", "counseling", "tinnitus retraining therapy", "cognitive behavioral therapy", "tinnitus activities treatment"라는 주제어를 사용하여 논문을 검 색하였다. 검색 결과, 총 5,283 편의 논문을 검색하였고 212 편의 중복된 논문을 제외하여 5,071편을 선별하였다. 이후 아홉 가 지의 제외 기준에 따라 5,040 편을 제외하였다. 선별 과정을 거 쳐 이명재훈련치료 관련 10 편, 인지행동치료 관련 13 편, 이명활 동치료 관련 8편을 최종 선정하여 총 31편의 논문을 리뷰하였 다(Figure 1).

\section{SUMMARY OF DATA}

\section{Tinnitus Retraining Therapy}

이명재훈련치료(TRT)란 이명에 대한 인식을 줄이고 삶의 질 에 미치는 이명의 부정적인 영향을 제거하기 위한 이명 중재법

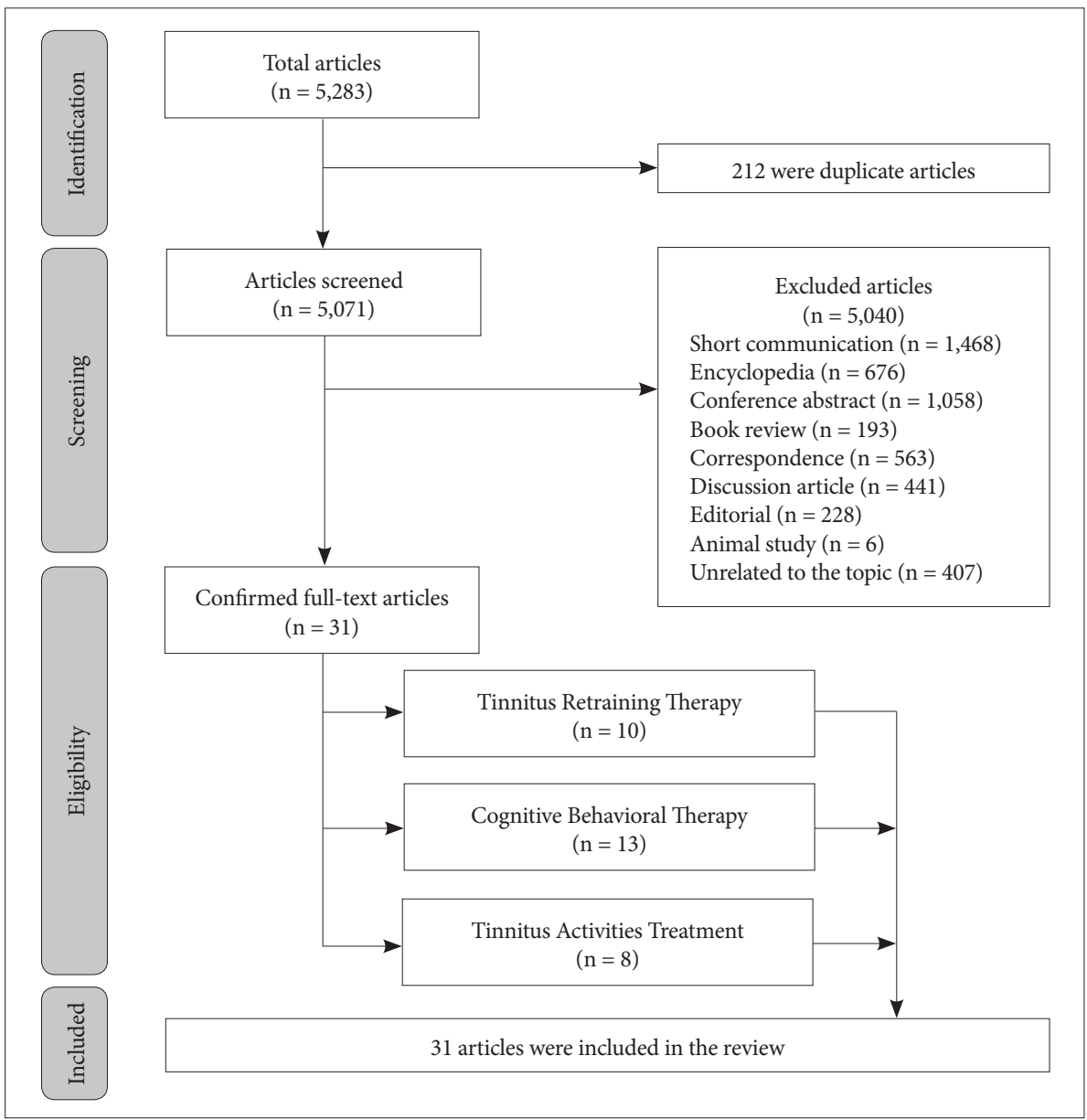

Figure 1. Flowchart showing the process of journal article selection. 
이다. 일반적으로 이명재훈련치료는 이명에 대한 지각을 낮추기 위한 소리치료와 이명으로 인한 부정적인 반응을 줄이기 위한 지시적 상담(directive counseling)으로 구성된다(Jastreboff \& Hazell, 1993; Scherer et al., 2014).

이명재훈련치료에서 소리치료의 역할은 이명의 습관화를 통 해 이명에 대한 지각을 낮추는 것이다. 조용한 곳에서 더 명확 하게 들리는 이명의 특성을 반영하여 이명과 비슷한 크기의 배 경음을 들려주는 방법으로 이명에 대한 반응의 습관화를 돕는 다(Jastreboff \& Jastreboff, 2000; Scherer et al., 2014). 소리치 료에서 사용되는 음원은 불편한 감정을 일으켜서는 안 되며, 이명대상자의 이명을 차폐(masking)하거나 청력역치와 비슷한 강도로 제시한다(Jastreboff \& Jastreboff, 2006). 이때 이명을 완전히 차폐할 수 있는 소리치료 음원의 크기는 오히려 이명을 악화시킬 수 있다(Bartnik \& Skarzynski, 2006). 소리치료를 시 행하기 위해 청력 손실을 가진 이명대상자에게 청각보조기기의 사용을 권할 수 있고, 청력 손실이 없는 대상자에게는 광대역 잡음(broadband noise) 등의 음원을 생성하는 소리발생기(sound generator)를 권할 수 있다(Jastreboff \& Jastreboff, 2006).

이명재훈련치료에서 지시적 상담의 역할은 이명대상자에게 습관화의 정의와 목적을 교육하여 대상자가 이명의 습관화를 이해하고 이명에 대한 부정적인 반응을 줄일 수 있도록 돕는 것이다(Scherer et al., 2014). 상담가는 이명에 집중하는 행동 이 변연계와 자율신경계를 자극하여 부정적인 반응을 촉진할 수 있다는 신경생리학적 메커니즘을 교육한다. 이명대상자는
이러한 메커니즘을 이해하고 이명에 덜 집중하거나 습관화할 수 있도록 유도하여 이명으로 인한 부정적인 반응을 줄일 수 있다(Jastreboff \& Hazell, 1993; Scherer et al., 2014). 지시적 상담은 교육적 후속 조치(educational follow-up session)의 단 계에 따라 일반적으로 6 12개월 동안 진행한다(Jastreboff, 2015; Makar et al., 2017). 지시적 상담의 교육 내용은 아래 Figure 2에 제시하였다.

첫 번째 세션에서 상담가는 이명재훈련치료의 초기 인터뷰 설문지(initial interview questionnaire)를 사용하여 대상자의 이명 종류와 고통의 정도를 확인할 수 있다(Henry et al., 2002). 상담가는 이명대상자가 이명뿐만 아니라 청각과민 및 청력 손 실의 문제도 겪고 있는지 확인할 수 있는 문항을 구성하고 이 명대상자에게 각각의 차이점을 설명한다. 이를 통하여 상담가 는 이명대상자가 청력 손실과 이명을 혼동하는 등의 오해를 제 거하여 이명에 대한 올바른 이해를 하도록 돕는다(Henry et al., 2002; Scherer et al., 2014). 첫 번째 세션의 목표는 이명에 대한 부정적인 생각이 변연계와 자율신경계를 활성화시켜 부 정적인 감정을 일으키고 이로 인해 이명의 인식과 성가심이 더 욱 악화될 수 있음을 이명대상자에게 교육하는 것이다. 상담가 는 이명의 원인을 신경생리학적 모델에 기초하여 설명하고, 대 상자가 이해한 정도에 따라 청각 시스템의 해부학적 구조와 뇌 의 기본적인 기능을 교육한다(Bartnik \& Skarzynski, 2006). 이러한 상담을 통해 이명대상자는 이명에 대한 올바른 정보를 얻을 수 있으며 부정적인 생각을 줄이거나 없애는 데 도움을

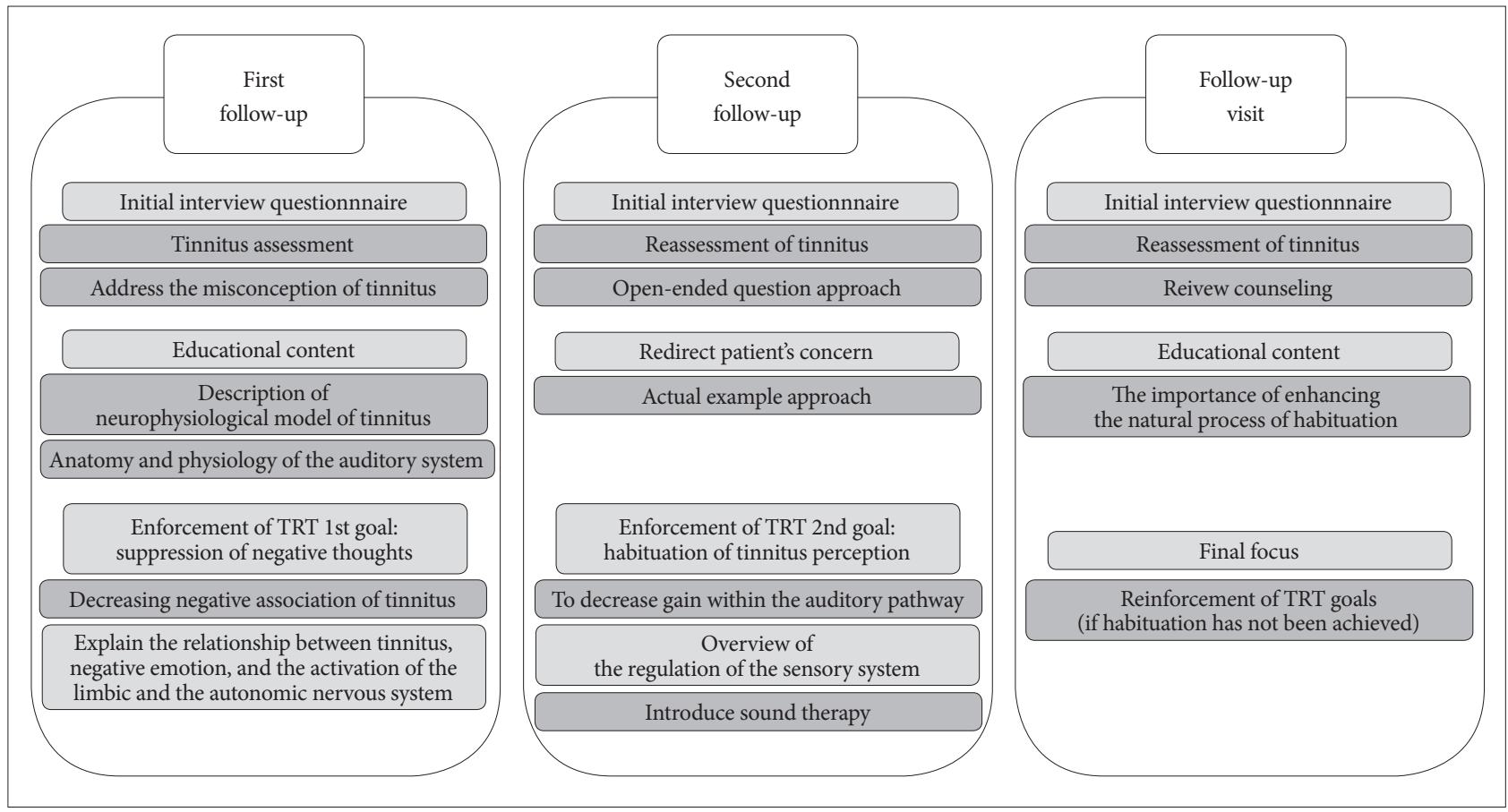

Figure 2. Contents of directive counseling in TRT according to the session. TRT: Tinnitus Retraining Therapy. 
받을 수 있다(Henry et al., 2002).

두 번째 세션의 목표는 이명대상자가 조용한 환경을 피해 이 명의 습관화를 촉진하는 것이다. 두 번째 세션에서 상담가는 진행 중인 이명재훈련평가의 결과 및 치료 진행 상황을 모니터 링하기 위해 초기 인터뷰 설문지를 재실시하고, 이를 토대로 이 명의 재평가와 상담을 진행한다(Henry et al., 2002). 상담가는 설문지를 통해 이명대상자가 이명으로 인해 현재 우려하고 있 는 사항이 무엇인지 확인한다. 예를 들어, 첫 번째 세션에서 청 각과민증(hyperacusis)이 가장 큰 우려사항인 이명대상자가 두 번째 세션의 재평가 결과에서는 청력 손실이 더 큰 우려사항으 로 바뀔 수 있다. 그러므로 상담가는 대상자의 현재 우려사항 을 확인하고 이를 반영하여 상담을 진행한다(Henry et al., 2002). 이때 상담가는 이명대상자의 이명에 대한 감정과 우려를 이해하기 위해 개방형 질문을 활용할 수 있다(예: ‘이명을 겪는 것으로 인해 어떠한 부정적인 생각을 갖게 되었나요?')(Bartnik \& Skarzynski, 2006). 만약 이명대상자가 이명 소리에 큰 스트 레스를 호소한다면, 상담가는 '처음 비가 내리기 시작할 때는 지붕 위에 떨어지는 빗방울 소리가 들리면서 그 소리를 신경 쓰 게 되지만, 시간이 흐를수록 빗방울 소리가 들리지 않게 되면 서 더 이상 신경 쓰지 않게 됩니다.와 같은 습관화의 실제 사례 를 사용하여 이명 소리가 익숙해지거나 무감각화될 수 있음을 이해시킬 수 있다. 상담가는 세션마다 이러한 상담을 통해 대상 자가 이명에 대한 부정적인 생각을 바꿀 수 있도록 돕는다(Shin $\&$ Lee, 2016). 또한 상담가는 이명대상자에게 귀마개 등을 사용 하여 귀를 과도하게 보호하는 것은 이명에 대한 인식을 더욱 악 화시킬 수 있다는 것 또한 교육한다(Bartnik \& Skarzynski, 2006; Henry et al., 2002). 더불어 이명대상자에게 주변 배경음 의 여부에 따라 이명의 인식이 어떻게 줄어들 수 있는지 교육하 면서 감각계의 제어(regulation of sensory system)와 소리치료 의 역할에 대해 설명한다(Jastreboff, 2011).

세 번째 세션의 목표는 이명의 습관화가 이루어졌는지 확인 하고, 상담을 통해 대상자에게 치료의 목표를 강조하여 대상자 가 지속적으로 이명재훈련치료를 수행하도록 동기를 부여하는 것이다(Henry et al., 2002). 세 번째 세션에서 상담가는 이전 세션과 같이 초기 인터뷰 설문지를 활용하여 이명대상자의 현 재 이명 종류와 우려를 확인하고, 이를 토대로 상담을 진행한 다(Henry et al., 2002). 세 번째 세션의 중재 기간은 대상자의 이명이 일상생활에 미치는 영향에 따라 조정할 수 있다(Bartnik \& Skarzynski, 2006). 세 번째 세션을 진행한 후에도 대상 자가 이명으로 인한 악영향이 심할 경우, 상담가는 추가 세션 을 통하여 이명재훈련치료의 목표인 습관화 과정을 위한 상담 을 지속할 수 있다. 예들 들어, 상담가는 일상생활에서 에어컨, 라디오, 소리발생기 등을 사용하여 이명대상자가 조용한 상황
을 피하고 자연스러운 습관화 과정을 경험하도록 상담할 수 있 다(Bartnik \& Skarzynski, 2006).

\section{Cognitive Behavioral Therapy}

인지행동치료(CBT)는 행동 변화와 인지적 구조조정을 통하 여 이명대상자의 이명에 대한 오해와 잘못된 인식을 제거하며 부정적인 반응을 바로잡는 이명 중재법이다(Sweetow, 1985). 인지행동치료에서 상담은 대상자의 이명으로 인한 긴장을 풀 어주고, 이명을 대하는 생각과 행동의 긍정적인 변화를 이끌어 내는 과제를 수행하여 부정적인 반응을 바로잡는 것을 목표로 한다(Andersson \& Kaldo, 2006). 선행연구에 의하면 인지행동 치료의 상담은 대상자에게 효과적인 동기부여를 위하여 시간 제한적인 중재법을 사용하며 24주 내에 6단계 세션으로 진행 한다(Andersson et al., 2002; Cully \& Teten, 2008). 본 리뷰에 서는 다양한 상담 요소 가운데 주로 사용하는 열 가지 구성 요 소인 교육(education), 적용이완(applied relaxation), 긍정적 상 상(positive imaginary), 인지적 구조조정(cognitive restructuring), 소리강화(sound enrichment), 이명 노출(exposure to tinnitus), 듣기전략(hearing tactics), 수면관리(sleep management), 집중(concentration) 및 재발방지(relapse prevention)에 대한 각각의 목표와 상담을 시행하는 순서와 방법을 제시하였 다(Andersson et al., 2002; Andersson \& Kaldo, 2006; Kaldo, 2008). 인지행동치료에서 상담의 열 가지 구성 요소들은 특정 한 순서가 있는 것은 아니지만, 일반적으로 이명대상자의 이해 를 돕기 위해 교육 요소를 초기 세션으로 구성하고 각 요소들 은 이명대상자의 필요에 따라서 선택적으로 적용하며 마지막 세션에서 재발방지 요소를 포함하도록 제안하고 있다(Andersson et al., 2002). 인지행동치료 내 상담의 열 가지 요소에 대 한 목적과 주요 내용은 아래 Figure 3에 제시하였다.

인지행동치료의 교육 요소에서 상담의 목표는 대상자에게 이명에 대한 정보를 제공하는 것이다. 이명의 원인 및 특징과 관 련된 정보는 대상자가 이명을 이해하도록 도울 수 있다(Tyler, 2006). 또한, 교육은 이명 중재를 시작하는 대상자가 갖고 있는 생각의 변화를 스스로 이끌어내는 인지적 구조조정과 과제 수 행을 통한 행동 변화의 필요성을 이해하도록 도울 수 있다. 인 지행동치료의 적용이완 요소에서 상담은 크게 깊은 이완(deep relaxation)과 빠른 이완(rapid relaxation)으로 나누어지며 주 로 6단계로 진행한다. 1 3단계는 깊은 이완으로, 1 단계는 이명 대상자가 근육의 긴장과 이완을 반복하여 자신의 근육을 인식 하고 조절한다. 2 단계는 이명대상자가 긴장하는 과정 없이 바 로 이완을 실시한다. 3 단계는 2 단계보다 더 빠르게 이완을 실 시하며, '쉬세요(relax)'와 같은 단서 단어를 사용하여 이명대상 자가 편안한 호흡 패턴을 만들 수 있도록 한다. 4 5단계는 빠 


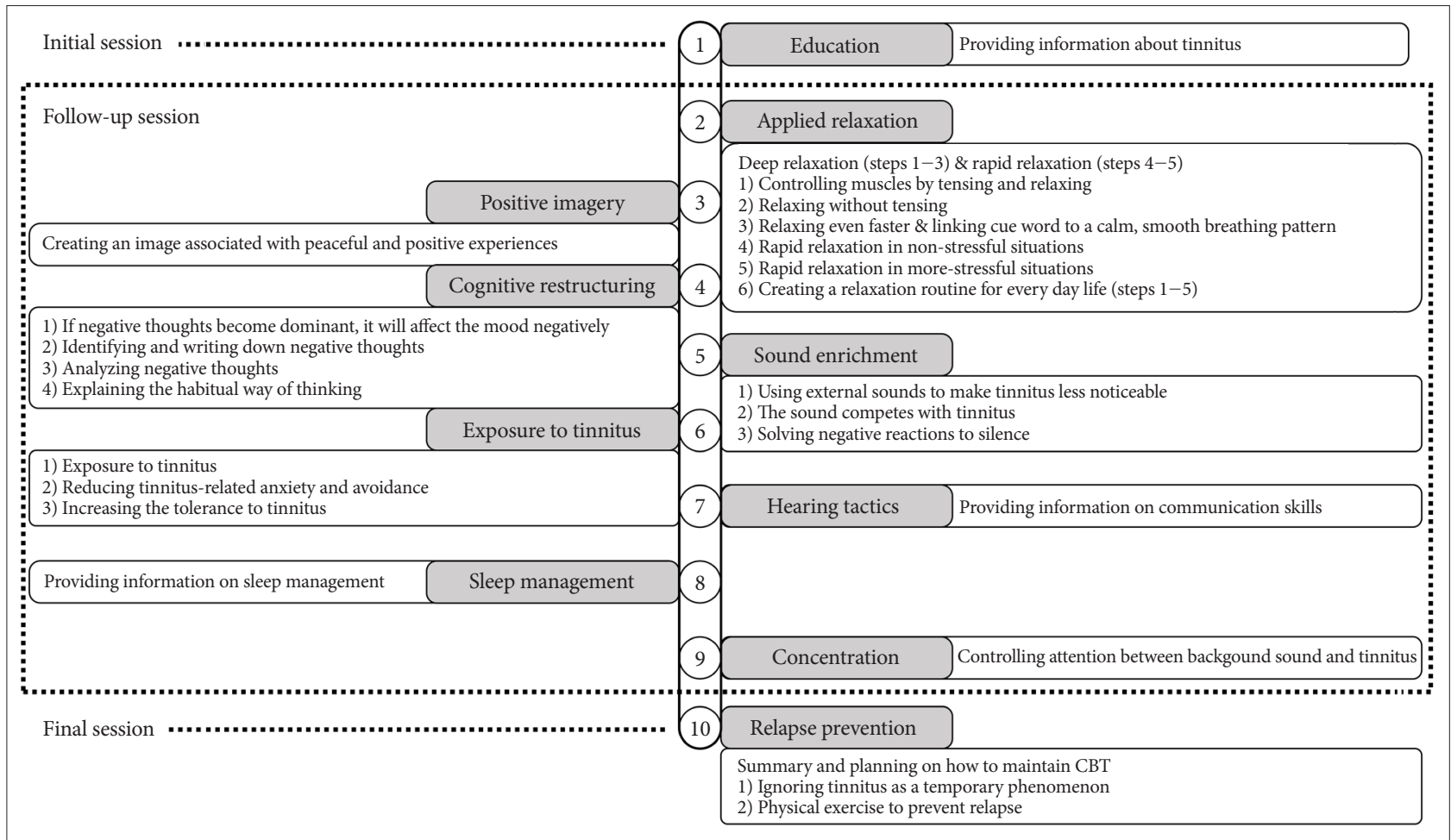

Figure 3. Counseling contents in CBT according to each component. CBT: Cognitive Behavioral Therapy.

른 이완으로, 4단계는 일상생활에서 빠르게 이완을 실시하는 훈련으로 진행하고, 5 단계는 이명으로 고통받는 일상생활에서 빠르게 이완을 실시할 수 있도록 훈련한다. 마지막 6단계는 이 명대상자가 스스로 매일 이완할 수 있는 습관을 만드는 것을 목표로 한다(Kaldo, 2008). 이러한 6단계의 적용이완은 대상자 의 이명으로 인한 긴장을 줄여주고 이명대상자가 스스로 이명 을 통제하고 처리할 수 있도록 돕는다(Davies et al., 1995). 인 지행동치료의 긍정적 상상 요소에서 진행하는 상담의 목표는 이명대상자의 긍정적인 생각을 증가시키는 것이다(Andersson $\&$ Kaldo, 2006). 눈을 감은 편안한 상태에서 긍정적인 이미지 를 만드는 것은 대상자가 이명에 대한 복잡하고 부정적인 생각에 서 벗어날 수 있는 능력을 가질 수 있도록 돕는다(Kaldo, 2008). 예를 들어, 이명대상자는 눈을 감고 나비가 꽃밭에서 평화롭게 날아다니는 모습 또는 양들이 푸른 풀밭에서 뛰어다니는 모습 등을 떠올릴 수 있다.

인지행동치료의 인지적 구조조정 요소에서 진행하는 상담의 목표는 이명대상자가 부정적인 생각에 사로잡혀 있지 않고 벗 어나도록 하는 것이다(Hawton et al., 1989). 이명대상자는 부 정적인 생각을 스스로 인식하고 작성하여 이명에 대한 부정적 인 생각들을 파악한다. 또한, 상담가는 이명대상자가 작성한 정 보를 통하여 대상자의 생각을 분석하여 이명대상자에게 새로 운 긍정적 사고방식과 태도를 제시한다(Kaldo, 2008). 이러한 과정을 통하여 상담가는 대상자가 이명에 대한 부정적인 생각
에서 벗어나도록 도울 수 있다(Andersson \& Kaldo, 2006). 인 지행동치료의 소리강화 요소에서 진행하는 상담은 환경음과 같 은 외부의 소리를 이용하여 대상자의 이명에 대한 인지를 줄이 는 것이다(Kaldo, 2008). 반대로 조용한 환경은 대상자에게 이 명이 들릴 수 있는 환경을 제공할 수 있다. 따라서, 상담가는 외 부의 소리를 통하여 대상자가 이명을 덜 인지할 수 있도록 돕는 다(Andersson et al., 2002; Andersson \& Kaldo, 2006). 인지행 동치료의 이명 노출 요소에서 진행하는 상담은 다음과 같다. 상 담의 목표는 대상자의 이명에 대한 내성을 증가시키는 것이다 (Kaldo, 2008). 이명대상자는 이명에 점진적으로 노출되어 이명 으로 인한 고통, 불안 및 회피를 줄일 수 있다. 궁극적으로 이명 에 대한 습관화를 통하여 내성을 증가시키고 이명대상자가 민 감하게 반응하는 것을 줄일 수 있도록 돕는다(Andersson et al., 1999). 인지적 구조조정과 소리강화, 이명 노출 요소는 이명 대상자가 이명에 대한 인지를 줄이는 데 도움을 줄 수 있다.

인지행동치료의 듣기전략 요소에서 진행하는 상담은 다음과 같다. 이명과 함께 청력 손실을 가진 대상자에게 듣기전략을 변 경하는 것은 이명으로 인하여 정보를 놓치던 대상자가 더 많은 의사소통 정보를 받아들일 수 있게 한다. 예를 들어, 대화하는 상대방에게 집중하는 것과 같은 의사소통전략은 이명으로 인 한 불편함을 덜어줄 수 있다. 이명대상자가 대화에 집중함으로 써 대화 능력을 강화하고 이명으로 인한 방해는 줄어들도록 한 다(Andersson \& Kaldo, 2006). 인지행동치료의 수면관리 요소 
에서 진행하는 상담은 다음과 같다. 이명과 함께 수면문제를 동반한 대상자는 이명으로 인하여 쉽게 잠에 들지 못하며 활동 시간에서의 수면부족으로 인한 피로, 스트레스와 같은 부정적 인 영향으로 인하여 삶의 질이 저하될 수 있다(Harvey, 2002). Henry \& Wilson(2002)은 '잠들기 전 책 읽기', '졸음이 올 때만 침대에 가기', '20분 내 수면 불가 시, 기상하기'와 같은 몇 가지 방법을 제시하였다. 올바른 수면관리는 이명대상자의 인지와 행동을 변화시킬 수 있고 이는 이명으로 인한 수면문제를 해결 하는 데 도움이 된다(Morin \& Bélanger, 2011). 인지행동치료 의 집중 요소에서 진행하는 상담은 대상자가 이명에 대한 집중 을 조절할 수 있는 능력을 갖도록 하는 것이다. 이명대상자는 이명이 들리는 상황에서 이명과 배경음 사이에 집중을 옮기는 훈련을 스스로 실시한다. 이를 통해 이명대상자가 이명 상황에 서 스스로 대처할 수 있는 능력을 가질 수 있도록 돕는다 $(\mathrm{Kal}-$ do, 2008). 마지막으로, 인지행동치료의 재발방지 요소에서 진 행하는 상담은 인지행동치료의 성공을 유지하고 재발에 대처 하는 방법을 요약 및 계획하는 것이다. 이명대상자는 앞에서 실시한 상담들을 통한 인지적 변화와 행동의 변화들을 일상생 활에 적용하여 이명을 더 이상 심각한 문제로 인지하지 않을 수 있다(Kaldo, 2008). 또한, 규칙적인 체력 운동은 이명대상자 의 자제력을 증가시켜 장기적으로 이명의 재발을 방지하는 데 도움이 될 수 있다(Gullette \& Blumenthal, 1996).

\section{Tinnitus Activities Treatment}

이명활동치료(TAT)란 이명대상자의 이명 및 관련된 문제를 사고와 감정(thoughts and emotions), 수면(sleep), 청각과 의사 소통(hearing and communication) 및 집중(concentration)의 네 가지 영역으로 나누고, 각 영역에 해당하는 정보를 통해 이 명에 대한 인식을 변화시키며, 각 영역의 어려움을 줄이기 위한
다양한 활동을 실시하여 이명의 부정적인 영향을 줄이는 이명 중재법이다(Tyler et al., 2006, 2007). 이명활동치료에서 이명대 상자에게 문제가 되는 영역을 결정하기 위해 이명활동설문지 (Tinnitus Activities Questionnaire)를 사용한다(Tyler et al., 2006, 2007). 이명활동설문지는 네 가지 영역, 총 20문항이 무 작위 순서로 구성되어 있으며, 0 100까지의 척도를 사용하고 점수가 클수록 해당 문항에 동의하는 것을 의미한다. 예를 들 어, 8 번 문항('나는 이명 때문에 우울하다)에서 100 점은 이 문 항에 완전히 동의하는 것을 의미하며, 0 점은 이 문항에 완전히 동의하지 않는 의미로 해석할 수 있다. 각 영역의 산출된 점수에 근거하여 상담가는 어느 영역에서 상담이 필요한지 결정하고, 선택한 영역과 관련된 중재 및 상담을 진행한다(Tyler et al., 2006, 2007). 이명활동치료는 정보 상담(informational counseling)과 참여 활동(activities engagement) 두 가지 요소로 구 성된다. 이명활동치료에서 상담은 각 영역에 해당하는 주요 정 보를 제공하는 것을 목적으로 하며 이명대상자는 이와 관련된 구체적인 활동들을 실시한다(Tyler et al., 2006, 2007). 이명활 동치료의 네 가지 영역에 따른 주요 상담 내용과 활동을 아래 Figure 4에 제시하였다.

이명활동치료의 사고와 감정 영역에서 진행하는 주요 상담 내용 및 활동은 다음과 같다. 상담가는 이명대상자와 자연스러 운 대화를 통해 상담을 진행한다(Tyler et al., 2006, 2007). 상 담가는 이명대상자에게 '이명이 당신의 삶에 어떤 영향을 주었 나요?', '당신은 어떤 정보를 원하나요?', ‘중재를 통해 기대하는 바가 무엇인가요?와 같은 구체적인 질문을 한다. 이러한 대화 는 상담 방향에 영향을 미치고 이명대상자가 마음을 열 수 있 도록 돕는다. 또한, 상담가는 이명에 대한 대상자의 생각과 반 응을 변화시키는 방법들을 설명한다. 예를 들어, 이명대상자는 새로운 모임에 참여하거나 평소에 원했던 여가활동이나 취미를

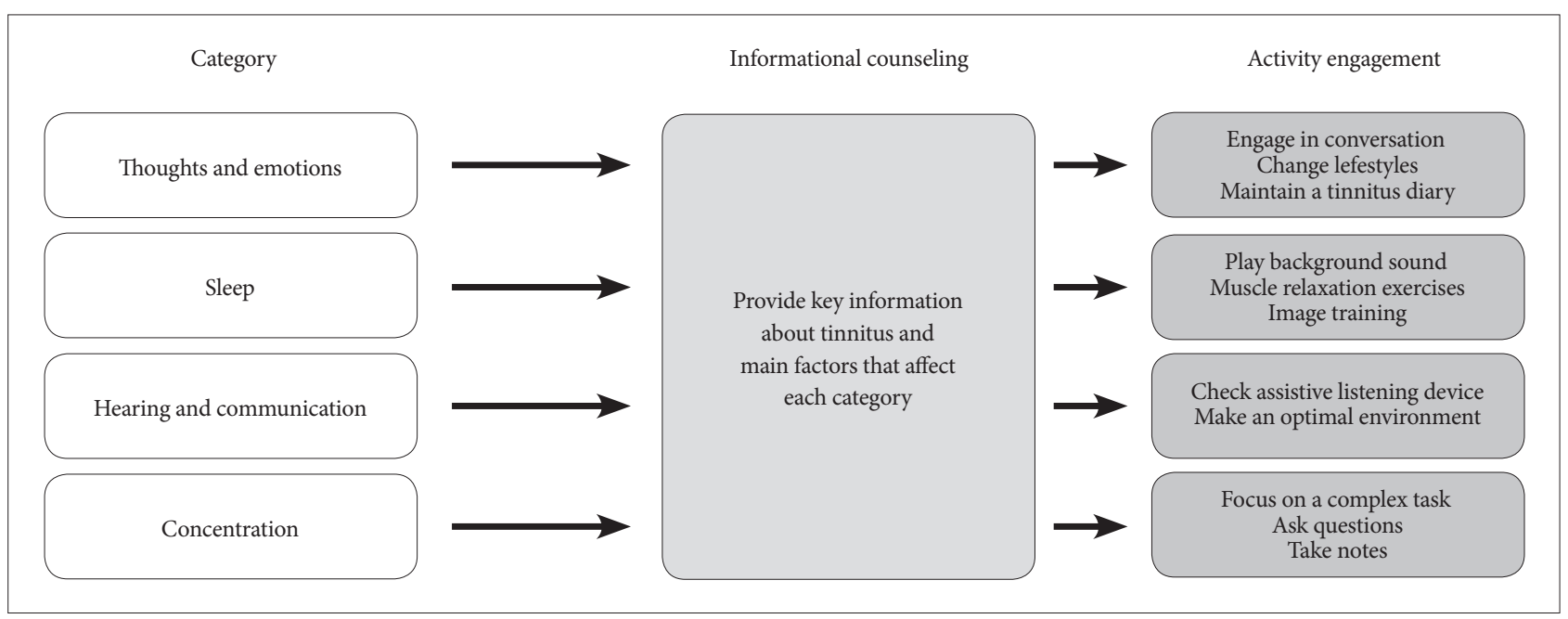

Figure 4. Counseling contents in Tinnitus Activities Treatment according to each category. 
시작할 수 있다. 이러한 활동은 대상자가 이명을 겪는 상황 속 에서도 생산적이고 행복한 삶을 살아갈 수 있다고 깨닫게 도울 수 있다. 더불어, 이명대상자는 이명 일지(tinnitus diary)를 작 성하여 이명이 나타나는 상황을 구분할 수 있다(Stouffer \& Tyler, 1990). 이명 일지의 구체적인 내용은 '이명에 대한 생각과 걱정을 적으십시오., '이러한 생각이 이명이 들리는 상황과 일치 하는지 확인하십시오., '이명이 들리지 않는 상황에 도움이 되 는 대체 사고 목록을 만드십시오.로 크게 세 가지 항목을 예로 들 수 있다. 이명 일지를 통해 대상자는 이명이 어떤 상황에서 들리는지 판별할 수 있으며, 각 상황에서 이명에 대한 본인의 생각과 감정을 스스로 확인할 수 있다.

이명활동치료의 수면 영역에서 진행하는 주요 상담 내용 및 활동은 다음과 같다. 상담가는 수면에 영향을 줄 수 있는 요소 들에 대한 정보를 이명대상자에게 제공하여 상담을 진행한다 (Tyler et al., 2006, 2007). 이러한 요소들의 예시는 이명대상자 의 식습관, 직업, 생활패턴과 침실의 조명, 주변 소음 및 온도와 같은 환경적 요인 등 매우 다양하다. 이명대상자가 낮잠을 자거 나 술과 카페인을 섭취하거나 폭식을 하는 경우도 잠들기 어려 운 대표적인 예가 된다. 잠들기 직전에 텔레비전을 시청하거나 컴퓨터를 사용하는 것과 같은 상황도 수면에 영향을 줄 수 있 다. 이와는 반대로, 이명대상자는 침실에 조용한 클래식 음악 이나 자연음과 같은 배경음악을 틀어 수면 환경을 조성할 수 있다(McKenna \& Daniel, 2006). 이러한 환경은 수면 직전의 이명이 뚜렷하게 들리는 상황을 줄여주며 수면 도중에 깨어난 대상자가 이명보다 배경음악을 더 인식하는 상황을 만들 수 있 도록 돕는다. 그 외에도 이명대상자는 이완 운동(relaxation exercises)과 이미지 트레이닝을 실시할 수 있다(Henry \& Wilson, 2002). 이완 운동의 예로는 발가락부터 발목, 종아리, 허벅 지, 신체 전부까지 규칙적인 호흡과 함께 근육의 긴장과 이완 을 반복해서 시행하는 점진적 근육 이완 운동이 있다. 이미지 트레이닝은 대상자가 특정한 공간이나 상황에 실제로 존재하 는 것처럼 상상하는 활동이다. 이러한 활동들을 통해 이명대상 자는 정신적 평안을 얻을 수 있고 잠드는 데 걸리는 시간을 단 축시킬 수 있다.

이명활동치료의 의사소통 영역에서 진행하는 주요 상담 내용 및 활동은 다음과 같다. 상담가는 이명과 관련된 의사소통의 어 려움을 설명하여 상담을 진행한다(Tyler et al., 2006, 2007). 상 담가는 이명과 청력 손실이 의사소통에 어떠한 영향을 끼치는 지에 대한 정보를 각각의 개념을 구별하여 제공한다. 상담가는 이명과 청력 손실을 동시에 겪고 있는 대상자에게 이명은 청력 손실을 유발하는 주요 원인이 아니며 청취 환경을 방해하여 의 사소통에 어려움을 줄 수 있음을 설명할 수 있다. 또한, 상담가 는 청력 손실이 있는 이명대상자가 적절한 청각보조기기를 착
용했는지 확인한다(Searchfield, 2006). 청각보조기기를 착용 한 이명대상자는 상담가를 통해 기기의 적합성, 기능의 정상작 동 여부, 제한점과 한계점을 알 수 있다. 이를 통해 이명대상자 는 의사소통에 어려움을 주는 요인이 이명인지 청취 환경인지 를 파악할 수 있다. 또한, 상담가는 의사소통에 필요한 최적의 환경이 무엇인지 이명대상자에게 설명할 수 있다. 최적의 의사 소통 조건은 주변 소음의 최소화, 시각적 방해 요소의 최소화, 대화 상대가 보이는 적절한 조명 등이 있다(Dillon, 2012). 이러 한 요소들은 이명대상자가 의사소통에 어려움을 겪는 상황을 줄일 수 있도록 돕는다.

이명활동치료의 집중 영역에서 진행하는 주요 상담 내용 및 활동은 다음과 같다. 상담가는 이명대상자에게 집중에 대한 정 보를 제공하여 상담을 진행한다(Tyler et al., 2006, 2007). 이명 대상자의 주변 환경 및 신체 상태에 따른 감정 상태가 이명이 들리지 않는 상황에서 집중에 어떤 영향을 끼치는지에 대한 정 보를 제공한다. 또한, 상담가는 이명대상자에게 주의 제어 접근 법(attention control approach)을 설명할 수 있다(Henry \& Wilson, 2001). 주의 제어 접근법이란 자기통제(self-control)에 의해 하나의 자극에서 다른 자극으로 주의를 전환할 수 있는 능력을 의미한다. 이명대상자는 다양한 활동을 통해 이명에서 다른 상황으로 집중할 수 있다. 대표적인 예로는 이명대상자는 복잡하고 어려운 특정 업무를 수행하여 이명 소리를 인식하기 보다 업무에 더 집중할 수 있다. 또한, 이명대상자는 어떤 일이 나 생활 중에서 적극적으로 그 상황에 참여하고, 질문하고, 메 모하는 것과 같은 활동을 실시할 수 있다. 이러한 활동은 이명 대상자가 이명에 덜 집중할 수 있도록 돕는다.

\section{DISCUSSIONS}

본 리뷰에서는 이명재훈련치료, 인지행동치료 및 이명활동치 료에서 진행하는 상담의 주요 목적, 절차 및 내용을 선행연구 분석을 통해 제시하였다(Appendix). 이명재훈련치료에서 상담 은 이명에 대한 부정적인 인식을 줄이고 이명에 대한 습관화를 돕는 것이 주요한 목적이었다. 인지행동치료에서 상담은 교육, 적용이완, 긍정적 상상, 인지적 구조조정, 소리강화, 이명 노출, 듣기전략, 수면관리, 집중 및 재발방지와 관련된 상담을 바탕으 로 이명에 대한 오해와 부정적인 감정을 제거하는 것이 주요한 목적이었다. 이명활동치료에서 상담은 이명대상자가 겪고 있는 이명과 이명으로 인한 문제를 사고와 감정, 수면, 의사소통 및 집중의 네 가지 영역으로 나누어 파악하고 대상자가 어려움을 겪고 있는 영역의 문제를 줄이기 위한 활동과 정보를 제공하여 삶의 질을 향상시키는 것이 주요한 목적이었다.

이명 관련 상담만의 효과를 제시한 연구는 매우 제한적이지 
만, 상담 과정을 포함하여 진행한 각 이명 중재법들은 다양한 결과로 이명의 개선 효과를 보고하였다(Table 1). Bauer et al. (2017)은 지시적 상담을 포함하는 이명재훈련치료 그룹과 이명 에 대한 정보 상담(기본적인 이명 정보)과 소리치료 없이 청각 보조기기만 사용한 그룹(standard of care, SC)으로 나누어 18개 월간 이명 중재를 실시하고 이명장애지수(Tinnitus Handicap Inventory, THI) 측정을 통하여 이명 중재 효과를 비교하였다. 연구 결과, 이명재훈련치료 그룹은 평균 $\mathrm{THI}$ 점수가 46.7점에 서 17.3점으로 29.4점이 감소하였으나 $\mathrm{SC}$ 그룹은 49.3점에서 33.4점으로 15.9 점이 감소하였다. 이는 이명재훈련치료에서 제 공하는 상담과 소리치료가 일반적인 상담과 청각보조기기 사 용에 비해 더 효과적인 중재법임을 보여주었다. 또 다른 예로, Tyler et al.(2012)는 이명재훈련치료 그룹, 완전차폐(total masking) 그룹 및 상담 그룹으로 나누어 12 개월간 이명 중재를 실시 하고 중재 전후에 측정한 이명장애설문지(Tinnitus Handicap Questionnaire, THQ) 점수 결과를 비교하였다. 이명재훈련치 료 그룹은 42.0점에서 33.0점으로 9.0점 감소, 완전차폐 그룹은 51.0점에서 32.0점으로 19.0점 감소, 상담 그룹은 47.0점에서 38.0점으로 9.0점 감소하였고 그룹 간 통계적 차이는 나타나지 않았다. 이러한 연구 결과는 상담이 이명 중재에서 중요한 역할 을 하고 있음을 보여준다. Andersson et al.(2005)은 인지행동 치료 그룹과 이명과 관련된 재활을 실시하지 않은 통제 그룹으 로 나누어 6주 동안 이명 중재를 실시하고 중재 전후에 측정한 이명반응설문지(Tinnitus Reaction Questionnaire, TRQ) 점수 를 비교하였다. 연구 결과, 인지행동치료 그룹의 TRQ 점수는 16.9점에서 9.7점으로 7.2점이 감소하였으며, 통제 그룹의 TRQ 점수는 29.4점에서 32.5점으로 3.1점이 오히려 증가하였다. 또
다른 예로, Li et al.(2019)은 인지행동치료와 소리치료를 함께 진행한 중재 그룹과 소리치료만 진행한 통제 그룹으로 나누어 6개월간 이명 중재를 실시하였다. 중재 효과의 비교는 THI 점 수를 사용하였으며 중재 그룹은 57.3점에서 35.8점으로 21.5점 감소하였고, 통제 그룹은 58.8점에서 48.7점으로 10.1점이 감소 하였다. 두 그룹 모두 유의미한 감소를 보였으나 인지행동치료 와 소리치료를 함께 진행한 중재 그룹이 더 크게 감소한 것으로 나타났다. Tyler et al.(2017)은 이명활동치료의 중재 및 상담 효과 를 검증하기 위하여 6개월간 중재를 진행하였으며 이명기능지수 (Tinnitus Functional Index, TFI), 이명장애설문지(THQ) 및 이명 주요기능설문지(Tinnitus Primary Function Questionnaire, $\mathrm{TPFQ})$ 를 사용하여 중재 전후에 각 설문지 점수를 측정하였다. 연구 결과, TFI 점수는 61.3점에서 35.3점으로 26.0점 감소, $\mathrm{THQ}$ 점수는 50.7에서 33.3점으로 17.4점 감소, TPFQ는 57.7에 서 32.2점으로 25.5 점이 감소하였다. 연구 결과, 모든 설문지 점 수에 유의미한 감소가 나타났다. Table 1에서 제시한 연구 결과 들 중 상담만의 효과를 제시한 연구는 하나지만(Tyler et al., 2012), 상담을 포함하는 각 이명 중재법에서 나타난 이명의 개 선 효과의 결과들은 상담이 이명 중재에서 중요한 역할을 하고 있음을 간접적으로 시사한다.

본문에서 제시한 각 이명 중재법 내 상담은 궁극적으로 이명 의 개선이라는 동일한 목적을 가지고 있지만, 상담의 주요 내용 에는 공통점과 차이점이 존재하는 것처럼 보인다. 이명재훈련 치료, 인지행동치료 및 이명활동치료에 포함된 주요 상담 내용 의 공통점과 차이점을 벤다이어그램에 분류하여 Figure 5에 제시하였다. 세 가지 이명 중재법의 상담은 공통적으로 교육, 이명 노출, 소리강화 및 재발방지 과정을 포함하고 있었다. 두

Table 1. Results of tinnitus intervention studies including counseling based on TRT, CBT, and TAT

\begin{tabular}{|c|c|c|c|c|c|c|}
\hline \multirow{2}{*}{ Reference } & \multirow{2}{*}{ Intervention } & \multirow{2}{*}{$\begin{array}{l}\text { Duration of } \\
\text { intervention }\end{array}$} & \multirow{2}{*}{ Criterion } & \multirow{2}{*}{ Group } & \multicolumn{2}{|c|}{ Main results* } \\
\hline & & & & & Pre-treatment & Post-treatment \\
\hline \multirow[t]{2}{*}{ Bauer et al. (2017) } & TRT & 18 months & THI & TRT $(\mathrm{n}=19)$ & 46.7 & 17.3 \\
\hline & & & & Standard of care $(n=19)$ & 49.3 & 33.4 \\
\hline \multirow[t]{3}{*}{ Tyler et al. (2012) } & TRT & 12 months & THQ & TRT with mixing-point $(\mathrm{n}=19)$ & 42.0 & 33.0 \\
\hline & & & & Total masking $(\mathrm{n}=11)$ & 51.0 & 32.0 \\
\hline & & & & Counseling $(\mathrm{n}=18)$ & 47.0 & 38.0 \\
\hline \multirow[t]{2}{*}{ Andersson et al. (2005) } & $\mathrm{CBT}$ & 6 weeks & TRQ & Treatment $(\mathrm{n}=12)$ & 16.9 & 9.7 \\
\hline & & & & Control $(\mathrm{n}=11)$ & 29.4 & 32.5 \\
\hline \multirow[t]{2}{*}{ Li et al. (2019) } & $\mathrm{CBT}$ & 6 months & THI & CBT and sound therapy $(\mathrm{n}=50)$ & 57.3 & 35.8 \\
\hline & & & & Sound therapy only $(\mathrm{n}=50)$ & 58.8 & 48.7 \\
\hline \multirow[t]{3}{*}{ Tyler et al. (2017) } & TAT & 6 months & TFI & TAT with chronic sensory & 61.3 & 35.3 \\
\hline & & & THQ & neural tinnitus $(\mathrm{n}=20)$ & 50.7 & 33.3 \\
\hline & & & TPFQ & & 57.7 & 32.2 \\
\hline
\end{tabular}

${ }^{*}$ Data are average score of criterion. THI: Tinnitus Handicap Inventory, THQ: Tinnitus Handicap Questionnaire, TRQ: Tinnitus Response Questionnaire, TFI: Tinnitus Functional Index, TPFQ: Tinnitus Primary Function Questionnaire, TRT: Tinnitus Retraining Therapy, CBT: Cognitive Behavioral Therapy, TAT: Tinnitus Activities Treatment 
Figure 5. Venn diagram for major counseling components of TRT, CBC, and TAT. TRT: Tinnitus Retraining Therapy, CBT: Cognitive Behavioral Therapy, TAT: Tinnitus Activities Treatment.

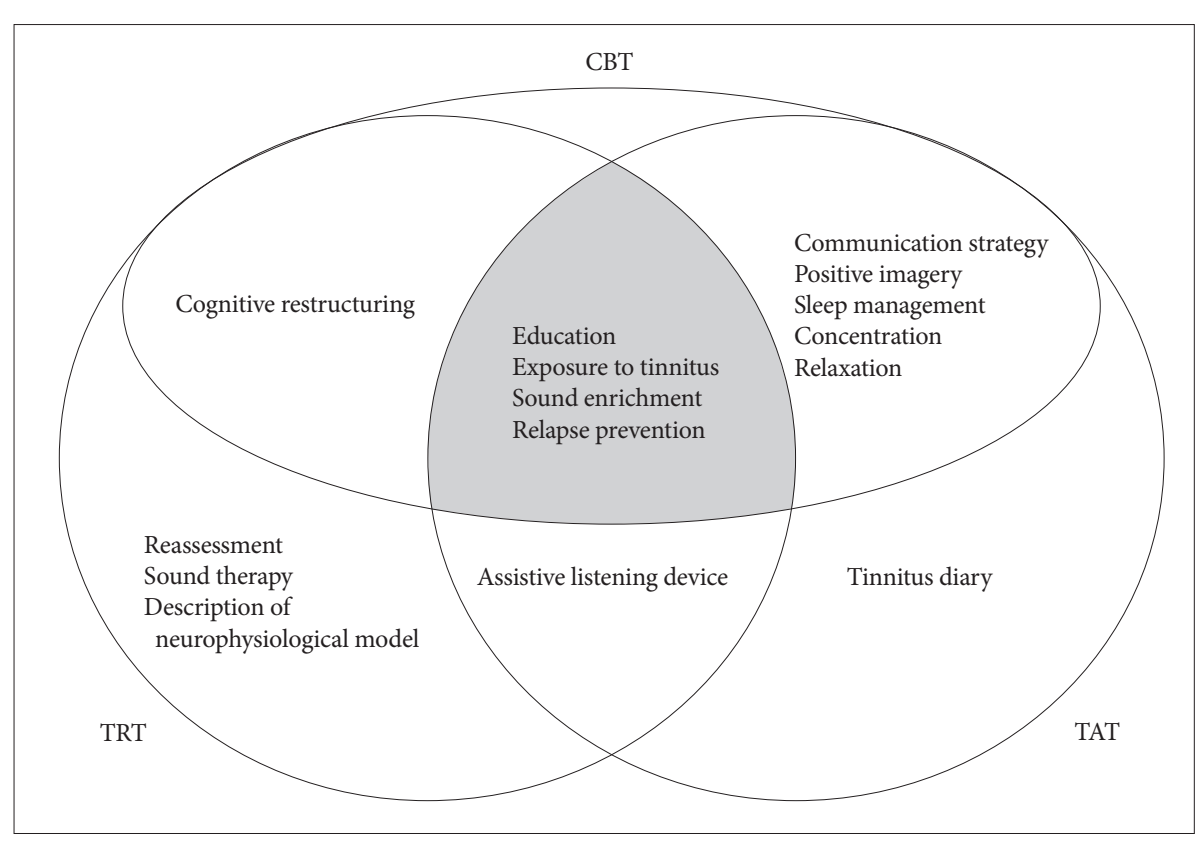

개의 중재법 내 상담에서 공통적으로 포함하는 내용으로는 인 지적 구조조정(이명재훈련치료, 인지행동치료) 및 청각보조기 기 사용(이명재훈련치료, 이명활동치료) 관련 상담이 있었다. 또한, 의사소통전략, 긍정적 상상, 수면관리, 집중, 적용이완 관 련 상담은 인지행동치료와 이명활동치료 내 상담에서 공통적 인 내용으로 포함하고 있었다. 공통점 외에도 각 중재법 내 상 담은 고유의 상담 내용을 포함하고 있었다. 이명재훈련치료의 상담은 재평가, 소리치료(소리치료 효과와 습관화 상담) 및 이 명의 신경생리학적 모델에 대한 설명이 고유한 내용으로 제시 되었다. 예를 들어, 신경생리학적 모델 설명과 소리치료 관련 상 담은 습관화에 초점을 둔 상담으로서 일반적인 이명 관련 교육 과 주변 환경음 청취와 같은 소리강화와는 차이가 있어 보인다. 이명활동치료의 상담은 이명이 나타나는 상황과 감정을 기록 하는 이명 일지 작성을 명확한 구성 요소로 제시하였다.

본 리뷰에서는 이명재훈련치료, 인지행동치료 및 이명활동치 료에서 보편적으로 포함하는 상담의 주요 내용과 절차를 다루 었으며, 이는 대상자의 특성에 따라 다양하게 조정하여 적용할 수 있을 것이다. 예를 들어, 이명재훈련치료를 진행 중인 대상자 가 이명으로 인해 의사소통과 관련된 어려움이 있다고 보고할 수 있다. 이때, 상담가는 이명재훈련치료 내 상담에는 주요 내 용으로 포함하고 있지 않지만 인지행동치료와 이명활동치료에 서 주로 포함하고 있는 의사소통전략을 현재 진행하고 있는 상 담에 추가할 수 있을 것이다. 또 다른 예로, 인지행동치료를 통 한 상담을 진행할 때, 대상자가 이명에 대한 부정적인 인식과 걱정이 주요한 관심사이고 수면장애가 없는 경우에 상담가는 교육, 적용이완, 긍정적 상상 및 인지적 구조조정을 상담의 주
요 내용으로 선택할 수 있을 것이다. 이때, 대상자는 이명에 대 한 올바른 이해와 이명을 대처하는 방법의 숙지를 통해 이명에 대한 걱정을 줄이고 부정적인 인식을 제거할 수 있을 것이다. 또한, 대상자는 수면장애가 없기 때문에 상담가는 수면관리를 상담의 주요 내용으로 포함할 필요는 없을 것이다. 각 이명 중 재법의 상담은 공통점과 차이점을 포함하여 다양한 내용과 절 차로 구성되어 있으며, 상담가는 대상자의 특성과 당면하고 있 는 어려움을 고려하여 상담의 주요 내용과 절차를 조정하여 진 행한다면 효율적인 상담을 진행할 수 있을 것이다.

본 리뷰에서는 이명재훈련치료, 인지행동치료, 이명활동치료 에 포함된 상담의 주요 내용을 정리하였다. 상담의 내용과 기 간 및 절차는 이명을 가진 개인에 따라 달라질 수 있지만, 본 리뷰는 청능사나 청각전문가가 이명 중재에 대한 상담의 주요 목적, 절차 및 내용을 이해하고 대상자 맞춤형 상담을 진행하 는데 도움을 줄 수 있을 것이다.

중심 단어 : 인지행동치료·상담·이명·이명활동치료·이명재훈 련치료.

\section{Ethical Statement}

N/A

\section{Acknowledgments}

N/A

\section{Declaration of Conflicting Interests}

There are no conflict of interests.

\section{Funding}

This work was supported by the National Research Foundation of Ko- 
rea grant funded by the Korean government (Ministry of Science and ICT; Grant NRF-2018R1C1B6003765).

\section{Author Contributions}

Conceptualization: In-Ki Jin. Data curation: all authors. Funding acquisition: In-Ki Jin. Investigation: Soon-Je Choi, Minseung Ku, TaeRim Lee, YeonWoo Sim, Jeeun Yoo, Nor Farawaheeda Ab Shukor, Yerim Shin. Project administration: Soon-Je Choi, In-Ki Jin. Validation: Soon-Je Choi, In-Ki Jin. Writing - original draft: Soon-Je Choi, Minseung Ku, TaeRim Lee, YeonWoo Sim, Jeeun Yoo, Nor Farawaheeda Ab Shukor, Yerim Shin. Writing - review \& editing: In-Ki Jin. Approval of final manuscript: all authors.

\section{ORCID iDs}

Soon-Je Choi In-Ki Jin

https://orcid.org/0000-0001-9507-3891

https://orcid.org/0000-0002-0834-5981

\section{REFERENCES}

Andersson, G. \& Kaldo, V. (2006). Cognitive-Behavioral Therapy with applied relaxation. In Tyler, R. S. (1st ed.). Tinnitus Treatment: Clinical Protocols (pp. 96-115). New York, NY: Thieme.

Andersson, G., Lyttkens, L., \& Larsen, H. C. (1999). Distinguishing levels of tinnitus distress. Clinical Otolaryngology and Allied Sciences, 24(5), 404-410.

Andersson, G., Porsaeus, D., Wiklund, M., Kaldo, V., \& Larsen, H. C. (2005). Treatment of tinnitus in the elderly: A controlled trial of cognitive behavior therapy. International Journal of Audiology, 44(11), 671675 .

Andersson, G., Strömgren, T., Ström, L., \& Lyttkens, L. (2002). Randomized controlled trial of internet-based cognitive behavior therapy for distress associated with tinnitus. Psychosomatic Medicine, 64(5), 810816.

Bartnik, G. M. \& Skarzynski, H. (2006). Tinnitus Retraining Therapy. In Tyler, R. S. (1st ed.). Tinnitus Treatment: Clinical Protocols (pp. 133145). New York, NY: Thieme.

Bauer, C. A., Berry, J. L., \& Brozoski, T. J. (2017). The effect of Tinnitus Retraining Therapy on chronic tinnitus: A controlled trial. Laryngoscope Investigative Otolaryngology, 2(4), 166-177.

Cully, J. A. \& Teten, A. L. (2008). A Therapist's Guide to Brief Cognitive Behavioral Therapy. (1st ed.), (pp. 6-9). Houston, TX: Department of Veterans Affairs South Central MIRECC.

Davies, S., McKenna, L., \& Hallam, R. S. (1995). Relaxation and cognitive therapy: A controlled trial in chronic tinnitus. Psychology and Health, 10(2), 129-143.

Dillon, H. (2012). Hearing Aids. (2nd ed.), (pp. 384-388). New York, NY: Thieme.

Gullette, E. C. \& Blumenthal, J. A. (1996). Exercise therapy for the prevention and treatment of depression. Journal of Psychiatric Practice ${ }^{\circledR}, 2(5)$, 263-271.

Harvey A. G. (2002). A cognitive model of insomnia. Behaviour Research and Therapy, 40(8), 869-893.

Hawton, K. E., Salkovskis, P. M., Kirk, J. E., \& Clark, D. M. (1989). Cognitive Behaviour Therapy for psychiatric problems: a practical guide. Oxford: Oxford University Press.

Henry, J. A., Jastreboff, M. M., Jastreboff, P. J., Schechter, M. A., \& Fausti, S. A. (2002). Assessment of patients for treatment with Tinnitus Retraining Therapy. Journal of the American Academy of Audiology, 13(10), 523-544.

Henry, J. L. \& Wilson, P. H. (2001). The Psychological Management of Chronic Tinnitus: A Cognitive Behavioral Approach. (1st ed.), (pp. 77-80). Boston, MA: Allyn and Bacon.

Henry, J. L. \& Wilson, P. H. (2002). Tinnitus: A Self-Management Guide for the Ringing in Your Ears. (1st ed.), (pp. 60-202). Boston, MA: Allyn and Bacon.

Jastreboff, P. J. (2011). Tinnitus Retraining Therapy. In Møller, A. R., Langguth, B., DeRidder, D., \& Kleinjung, T. (1st ed.). Textbook of Tinnitus (pp. 575-596). New York, NY: Springer Sciences \& Business Media.

Jastreboff, P. J. (2015). 25 years of tinnitus retraining therapy. HNO, 63(4), 307-311.

Jastreboff, P. J. \& Hazell, J. W. (1993). A neurophysiological approach to tinnitus: Clinical implications. British Journal of Audiology, 27(1), 7-17.

Jastreboff, P. J. \& Jastreboff, M. M. (2000). Tinnitus Retraining Therapy (TRT) as a method for treatment of tinnitus and hyperacusis patients. Journal of the American Academy of Audiology, 11(3), 162-177.

Jastreboff, P. J. \& Jastreboff, M. M. (2006). Tinnitus Retraining Therapy: A different view on tinnitus. ORL; Journal for Oto-Rhino-Laryngology and Its Related Specialties, 68(1), 23-30.

Kaldo, V. (2008). Cognitive Behavioural Therapy as Guided Self-Help to Reduce Tinnitus Distress. Uppsala: Acta Universitatis Upsaliensis.

Lee, Y., Kim, T., Lee, K., Jeon, S., Jo, S., \& Jin, I. K. (2020). The pathophysiology of tinnitus: Involvement of the somatosensory, brain, and limbic systems. Audiology and Speech Research, 16(1), 11-18.

Li, J., Jin, J., Xi, S., Zhu, Q., Chen, Y., Huang, M., et al. (2019). Clinical efficacy of Cognitive Behavioral Therapy for chronic subjective tinnitus. American Journal of Otolaryngology, 40(2), 253-256.

Makar, S. K., Mukundan, G., \& Gore, G. (2017). Treatment of tinnitus: A scoping review. The International Tinnitus Journal, 21(2), 144-156.

Martinez-Devesa, P., Perera, R., Theodoulou, M., \& Waddell, A. (2010). Cognitive Behavioural Therapy for tinnitus. The Cochrane Database of Systematic Reviews, 9, CD005233.

McFadden, D. (1982). Tinnitus: Facts, Theories, and Treatments. (pp. 699). Washington, DC: National Academies Press.

McKenna, L. \& Daniel, H. C. (2006). Tinnitus-related insomnia treatment. In Tyler, R. S. (1st ed.). Tinnitus Treatment: Clinical Protocols (pp. 81-95). New York, NY: Thieme.

Morin, C. M. \& Bélanger, L. (2011). Cognitive therapy for dysfunctional beliefs about sleep and insomnia. In Perlis, M. L., Aloia, M., \& Kuhn, B. (1st ed.). Behavioral Treatments for Sleep Disorders: A Comprehensive Primer of Behavioral Sleep Medicine Interventions. (pp. 107-118). Cambridge, MA: Academic Press.

Scherer, R. W., Formby, C., Gold, S., Erdman, S., Rodhe, C., Carlson, M., et al. (2014). The Tinnitus Retraining Therapy trial (TRTT): Study protocol for a randomized controlled trial. Trials, 15, 396.

Searchfield, G. D. (2006). Hearing aids and tinnitus. In Tyler, R. S. (1st ed.). Tinnitus Treatment: Clinical Protocols (pp. 161-175). New York, NY: Thieme.

Stouffer, J. L. \& Tyler, R. S. (1990). Characterization of tinnitus by tinnitus patients. The Journal of Speech and Hearing Disorders, 55(3), 439-453.

Shin, J. W. \& Lee, H. K. (2016). Tinnitus Retraining Therapy. Hanyang Medical Reviews, 36(2), 120-124.

Sweetow R. (1985). Counseling the patient with tinnitus. Archives of Otolaryngology, 111(5), 283-284.

Tyler, R. S. (2006). Neurophysiological models, psychological models, and treatments for tinnitus. In Tyler, R. S. (1st ed.). Tinnitus Treatment: Clinical Protocols (pp. 1-22). New York, NY: Thieme.

Tyler, R. S., Deshpande, A. K., Lau, C. C., \& Kuk, F. (2017). The effectiveness of the progression of Widex Zen Tinnitus Therapy: A pilot study. American Journal of Audiology, 26(3), 283-292.

Tyler, R. S., Gehringer, A. K., Noble, W., Dunn, C. C., Witt, S. A., \& Bardia, A. (2006). Tinnitus activities treatment. In Tyler, R. S. (1st ed.). Tinnitus Treatment: Clinical Protocols (pp.116-132). New York, NY: Thieme.

Tyler, R. S., Gogel, S. A., \& Gehringer, A. K. (2007). Tinnitus activities treatment. Progress in Brain Research, 166, 425-434.

Tyler, R. S., Noble, W., Coelho, C. B., \& Ji, H. (2012). Tinnitus retraining therapy: Mixing point and total masking are equally effective. Ear and Hearing, 33(5), 588-594. 


\section{APPENDIX $\square$}

\section{List of References for Tinnitus Interventions}

\begin{tabular}{|c|c|c|c|}
\hline $\begin{array}{l}\text { Tinnitus } \\
\text { intervention }\end{array}$ & Author & Year & Title \\
\hline \multirow{10}{*}{ TRT } & Makar et al. & 2017 & Treatment of tinnitus: A scoping review \\
\hline & Shin \& Lee & 2016 & Tinnitus Retraining Therapy \\
\hline & Jastreboff & 2015 & 25 years of Tinnitus Retraining Therapy \\
\hline & Scherer et al. & 2014 & $\begin{array}{l}\text { The Tinnitus Retraining Therapy Trial (TRTT): Study protocol for } \\
\text { a randomized controlled trial }\end{array}$ \\
\hline & Jastreboff & 2011 & $\begin{array}{l}\text { Tinnitus Retraining Therapy. In Møller, A. R., Langguth, B., DeRidder, } \\
\text { D., \& Kleinjung, T. Textbook of Tinnitus. }\end{array}$ \\
\hline & Bartnik \& Skarzynski & 2006 & Tinnitus Retraining Therapy \\
\hline & Jastreboff \& Jastreboff & 2006 & Tinnitus Retraining Therapy: A different view on tinnitus \\
\hline & Henry et al. & 2002 & Assessment of patients for treatment with Tinnitus Retraining Therapy \\
\hline & Jastreboff \& Jastreboff & 2000 & $\begin{array}{l}\text { Tinnitus Retraining Therapy (TRT) as a method for treatment } \\
\text { of tinnitus and hyperacusis patients }\end{array}$ \\
\hline & Jastreboff \& Hazell & 1993 & A neurophysiological approach to tinnitus: Clinical implications \\
\hline \multirow{13}{*}{ CBT } & Morin \& Bélanger & 2011 & Cognitive therapy for dysfunctional beliefs about sleep and insomnia \\
\hline & Cully \& Teten & 2008 & A therapist's guide to brief Cognitive Behavioral Therapy \\
\hline & Kaldo & 2008 & $\begin{array}{l}\text { Cognitive Behavioural Therapy as guided self-help to reduce } \\
\text { tinnitus distress }\end{array}$ \\
\hline & Andersson \& Kaldo & 2006 & Cognitive-Behavioral Therapy with applied relaxation \\
\hline & Tyler & 2006 & $\begin{array}{l}\text { Neurophysiological models, psychological models, and treatments } \\
\text { for tinnitus }\end{array}$ \\
\hline & Andersson et al. & 2002 & $\begin{array}{l}\text { Randomized controlled trial of internet-based Cognitive Behavior } \\
\text { Therapy for distress associated with tinnitus }\end{array}$ \\
\hline & Harvey & 2002 & A cognitive model of insomnia \\
\hline & Henry \& Wilson & 2002 & Tinnitus: A self-management guide for the ringing in your ears \\
\hline & Andersson et al. & 1999 & Distinguishing levels of tinnitus distress \\
\hline & Gullette \& Blumenthal & 1996 & Exercise therapy for the prevention and treatment of depression \\
\hline & Davies et al. & 1995 & Relaxation and cognitive therapy: A controlled trial in chronic tinnitus \\
\hline & Hawton et al. & 1989 & $\begin{array}{l}\text { Cognitive Behavioural Therapy for psychiatric problems: } \\
\text { A practical guide }\end{array}$ \\
\hline & Sweetow & 1985 & Counselling the patient with tinnitus \\
\hline \multirow{8}{*}{ TAT } & Dillon & 2012 & Hearing Aids \\
\hline & Tyler et al. & 2007 & Tinnitus activities treatment \\
\hline & McKenna \& Daniel & 2006 & $\begin{array}{l}\text { Tinnitus-related insomnia treatment. In Tyler, R. S. Tinnitus } \\
\text { Treatment: Clinical Protocols. }\end{array}$ \\
\hline & Searchfield & 2006 & $\begin{array}{l}\text { Hearing aids and tinnitus. In Tyler, R. S. Tinnitus Treatment: Clinical } \\
\text { Protocols. }\end{array}$ \\
\hline & Tyler et al. & 2006 & Tinnitus activities treatment \\
\hline & Henry \& Wilson & 2002 & Tinnitus: A self-management guide for the ringing in your ears \\
\hline & Henry \& Wilson & 2001 & $\begin{array}{l}\text { The psychological management of chronic tinnitus: } \\
\text { A cognitive-behavioral approach }\end{array}$ \\
\hline & Stouffer \& Tyler & 1990 & Characterization of tinnitus by tinnitus patients \\
\hline
\end{tabular}

